\title{
Experimental study of separation of ammonia synthesis vent gas by hydrate formation
}

\author{
Dong Taibin, Wang Leiyan, Liu Aixian, Guo Xuqiang*, Ma Qinglan, \\ Li Guowen and Sun Qiang
}

State Key Laboratory of Heavy Oil Processing, China University of Petroleum, Beijing 102249, China

\begin{abstract}
Termodynamic data on methane hydrate formation in the presence of ammonia are very important for upgrading of ammonia synthesis vent gas using hydrate formation. This paper is focused on the formation conditions of methane hydrate in the presence of ammonia and the effects of gas-liquid ratio and temperature on the separation of vent gas by hydrate formation. Equilibrium data for methane hydrate within an ammonia mole concentration range from $1 \%$ to $5 \%$ were obtained. The experimental results indicated that ammonia has an inhibitive effect on hydrate formation. The higher the ammonia concentration, the higher is the pressure reguired for methane hydrate formation would be. The primary experimental results showed that when volume ratio of gas to liquid was 80:1 and temperature was 283.15 $\mathrm{K}$, total mole fraction of $\left(\mathrm{H}_{2}+\mathrm{N}_{2}\right)$ in gas phase could reach $96.9 \%$.
\end{abstract}

Key words: $\mathrm{CH}_{4}$ hydrate, ammonia, THF, thermodynamics, separation

\section{Introduction}

Only about $20 \%$ of the hydrogen and nitrogen reacts on the first pass through the Haber process, and the unreacted hydrogen and nitrogen is recycled after removal of the ammonia product. Continuous recycling of the unreacted $\mathrm{H}_{2}$ and $\mathrm{N}_{2}$ is part of the normal process. Inert gases like argon and methane build up in the recycling process, and have to be removed out as "Vent gas" to keep the conversion efficiency high.

A typical vent gas composition from the Haber process is $65 \%$ hydrogen, $23 \%$ nitrogen, $9 \%$ methane and $2.4 \%$ argon (mole fraction). Normal industrial procedure is for the bulk of the hydrogen in the vent gas to be recovered by membrane filtration and the residual hydrogen and methane along with the inert nitrogen and argon is burnt for process heat, unless it is economic to recover the argon as an industrial gas.

If a proportion of the inert gases (argon and methane), can be removed from the vent gas, the remaining $\mathrm{H}_{2}$ and $\mathrm{N}_{2}$ can be fed back into the recycled gas stream to be reacted again. Using hydrate formation to reduce the concentrations of both $\mathrm{Ar}$ and $\mathrm{CH}_{4}$ offers an opportunity to recycle more of the hydrogen and nitrogen, and perhaps to recover argon and methane efficiently.

Gas hydrates are non-stoichiometric compounds formed by low-molecular-weight gases and water at low temperature and high pressure (Sloan, 1990). In the oil and gas industry hydrates have historically been regarded as an obstacle as methane hydrate can block gas pipelines and cause tubing and casing expand/burst during natural gas transportation

*Corresponding author. email: guoxq@cup.edu.cn

Received October 31, 2008
(Hammerschmidt, 1934; Chatti et al, 2005; Makogon, 1965). One $\mathrm{m}^{3}$ of solid metnane hydrate typically contains $167 \mathrm{~m}^{3}$ of gas at standard temperature and pressure (STP) (Englezos, 1993; Lee et al, 2003), which may perhaps lead to its consideration as an alternative means to transport and store natural gas (Lee et al, 2003; Rovetto et al, 2006; Strobel et al, 2006; Florusse et al, 2004; Makogon, 1981). Because different gases form hydrates under different pressures at a given temperature, hydrate formation has been considered as a possible way to separate gas mixtures (Kim et al, 2007). When a gas mixture form a hydrate with water under specific conditions, the components that can form hydrate more easily will be enriched in the hydrate phase. For new technologies based on hydrates to be developed, for example, avoiding the problems associated with hydrate formation and using the hydrates as an energy resource, the phase equilibrium data in pure water and aqueous systems containing inhibitors such as electrolytes should be acquired. A number of researchers have been involved in the work of hydrate thermodynamics concerning aqueous systems with inhibitors (Sun et al, 2007; Ng and Robinson, 1985; Song and Kobayashi, 1989; Dholabhai and Bishnoi, 1994; Clarke et al, 2004; Zhang et al, 2004).

This study is a part of an ongoing experimental and computational program on hydrate formation in ammoniawater systems. A new method of separating and recycling the vent gas of ammonia synthesis by forming/dissociating hydrate is investigated. We studied the hydrate-forming conditions of methane in $\left(\mathrm{NH}_{3}+\mathrm{H}_{2} \mathrm{O}\right)$ system and found that the hydrate-forming pressure of methane is too high to be practically applicable. Tetrahydrofuran (THF) is miscible with water and could form structure II hydrate at a molar THF to $\mathrm{H}_{2} \mathrm{O}$ ratio of 1:17 (Mahmoodaghdam and Bishnoi, 2002). THF is proved to be a hydrate stabilizer (Hashimoto 
and Murayama, 2006). It can greatly lower the hydrateforming pressure and increase the corresponding hydrate formation rate. The hydrate-forming condition of methane in $\left(\mathrm{NH}_{3}+\mathrm{H}_{2} \mathrm{O}+\mathrm{THF}\right)$ system was investigated in this paper, which might be a guide for separation of exhaust gas mixture of ammonia plant by forming and then dissociating hydrate.

\section{Experimental apparatus}

A schematic diagram of the apparatus used in this experiment is illustrated in Fig. 1. A high-pressure cell was immersed in an air bath. The cell was made of stainless steel with an inner volume of $220 \mathrm{~mL}$ separated to two parts by a piston. Two rectangle observation windows were fixed at the front and back of the lower section of the cell. The piston can be moved up/down to change the pressure in the cell. A manual pressure liquid pump was used to transfer pressurized liquid (ethylene glycol solution with a mass fraction of $28 \%$ ethylene glycol) to the upper part to adjust the piston position and control the pressure. The accuracy of temperature measurement was $\pm 0.1 \mathrm{~K}$. A pressure sensor made by Shanghai Seaso Digital Technology Co., Ltd. was used for the measurement of pressure. The range of the pressure gauge was from 0 to 20 $\mathrm{MPa}$ with an accuracy of $0.1 \%$. There was a magnetic stirrer at the bottom of the cell for blending liquid and gas.

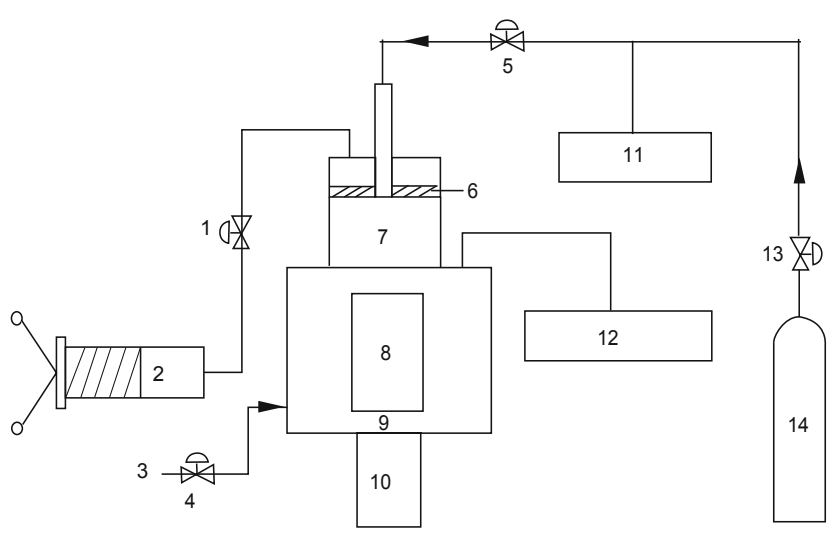

Fig. 1 Schematic diagram of the experimental apparatus 1,4,5,13-valve; 2-manual pressure liquid pump; 3-inlet/outlet for liquid; 6-piston; 7-reaction vessel; 8-glass window; 9-magnetic stirrer; 10electromotor; 11-pressure sensor; 12-temperature sensor; $14-\mathrm{CH}_{4}$ gas cylinder

\section{Materials and preparation of samples}

Reagents used in the experiment, including the purity and supplier, are given in Table 1. Distilled water used for preparing the aqueous solution was boiled for half an hour to expel the dissolved air.

Table 1 Purity and supplier of the gas or reagent used in experiment

\begin{tabular}{|c|c|c|}
\hline Components & Purity & Producer \\
\hline $\mathrm{CH}_{4}$ & $99.99 \%$ & Beijing AP Beifen Gases Industry Co., Ltd., China \\
\hline $\mathrm{Ar}$ & $99.99 \%$ & Beijing AP Beifen Gases Industry Co., Ltd., China \\
\hline $\mathrm{N}_{2}$ & $99.99 \%$ & Beijing AP Beifen Gases Industry Co., Ltd., China \\
\hline $\mathrm{H}_{2}$ & $99.99 \%$ & Beijing AP Beifen Gases Industry Co., Ltd., China \\
\hline Deionized water & $15 \times 10^{6} \Omega \cdot \mathrm{cm}$ & Prepared by water distillation (SZ-93, Shanghai Yarong Biochemistry Instrument Factory, China) \\
\hline Ammonia-water & Analytical pure & Guangdong Xilong Chemical Co., Ltd., China \\
\hline THF & Analytical pure & Beijing Reagents Corporation, China \\
\hline
\end{tabular}

\section{Experimental procedures}

\subsection{Measurement of methane hydrate-forming conditions}

First, the cell was washed by de-ionized water and rinsed three times with the liquid sample used in experiment. Then, the cell was evacuated for 30 minutes and purged with methane three times to ensure the absence of air in the pipeline and cell. After that, the liquid sample and methane were charged into the cell until the designated pressure was reached. Then the air-bath temperature was set to a designated value. When the temperature of the cell was stable, the hydrate formation point was measured by the pressure-searching method (Song and Kobayashi, 1989). The pressure in the cell was raised to $1 \mathrm{MPa}$ higher than the estimated equilibrium pressure by pushing the piston with the pump. When hydrate crystals could be seen, the pressure was reduced gradually to make the hydrate crystals decompose slowly. When all the hydrate crystals disappeared, the pressure of the system was elevated again with a small pressure-step of $0.01 \mathrm{MPa}$. If a hydrate crystal could remain for $6 \mathrm{hrs}$ at a given temperature and pressure and would disappear when the pressure was reduced by a maximum of $0.01 \mathrm{MPa}$, then the pressure and temperature of the system were taken as the equilibrium hydrate formation conditions. The above procedures were repeated at a series of temperature. 


\subsection{Upgrading of ammonia synthesis vent gas by hydrate formation}

First, a hydrogen, nitrogtn, methane and argon gas mixture was prepared with a composition typical of ammonia synthesis vent gas (see Table 4). The reaction vessel and pipeline were rinsed three times with liquid sample and the gas mixture, respectively, and a specific amount of liquid and gas mixture were injected into the vessel. The temperature was set to a designated value through the air-bath. The reaction started as soon as the stirrer began to work. The stirring velocity and vapor pressure must be kept invariable in the entire reaction process. When the pressure of vapor did not change with time, the reaction could be regarded as terminated. At this time the vapor sample was taken out and its composition was measured by gas chromatography (GC). Then the temperature of the air bath was set to $268.15 \mathrm{~K}$ and kept for 1 hour, and the vapor was released at once, and the vessel was evacuated again. Then, the temperature was set to a higher value to ensure the gas hydrate dissociated completely, and the gas sample of the hydrate phase was taken out. The composition of hydrate was measured with GC.

\section{Experimental results}

\subsection{Methane hydrate formation pressures}

Experiments were firstly conducted with a pure watermethane system, and these results are listed in Table 2 and shown in Fig. 2. The results showed good agreement with literature (Devarakonda et al, 1999; Thakore and Holder, 1987).

Table 2 Methane hydrate equilibrium conditions

\begin{tabular}{cccc}
\hline, K & $P_{\text {exp }}$, MPa & $P_{\text {ref, }}$, MPa & Reference \\
\hline 278.2 & 4.49 & 4.50 & Devarakonda et al, 1999 \\
279.1 & 4.85 & & \\
279.2 & & 4.90 & Devarakonda et al, 1999 \\
280.4 & 5.54 & & \\
280.9 & & 5.77 & Thakore and Holder, 1987 \\
281.1 & 6.00 & & Devarakonda et al, 1999 \\
281.2 & & 6.1 & Thakore and Holder, 1987 \\
282.3 & & 6.65 & \\
\hline
\end{tabular}

Methane hydrate formation data were measured with $\left(\mathrm{NH}_{3}+\mathrm{H}_{2} \mathrm{O}\right)$ system and $\left(\mathrm{NH}_{3}+\mathrm{H}_{2} \mathrm{O}+\mathrm{THF}\right)$ system. The data are listed in Table 3 and shown in Fig. 3. It was obvious that the presence of ammonia made hydrate formation more difficult compared with that in pure water (Table 2) under

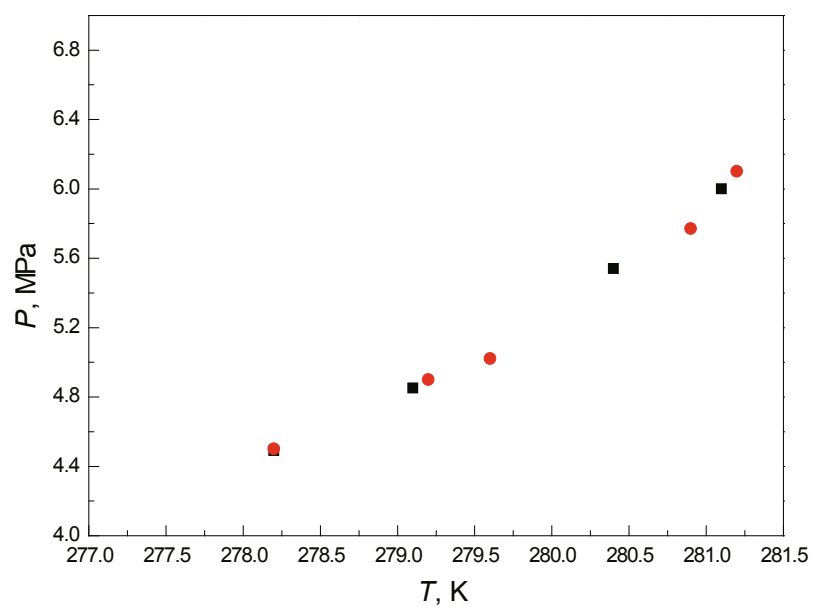

Fig. 2 Pressure-temperature phase equilibrium of methane hydrate formation in pure water

mexperimental data; •data from literature (Devarakonda et al, 1999; Thakore and Holder, 1987)

the same conditions. Ammonia acted as an inhibitor in the process of hydrate formation. The higher the concentration of ammonia was, the higher the pressure for methane hydrate formation would be. However, the hydrate-forming pressure would be lower greatly in the presence of THF, making it possible in an industrial application for separation of vent gas of ammonia synthesis by hydrate formation.

For these systems, the concentrations of ammonia and water in the vapor phase were all very small, so the vapor phase was assumed to be pure methane. It was also found that the quantity of hydrates at equilibrium was negligibly small. Consequently, it was assumed that the concentration of ammonia solution at equilibrium state was identical to the initial concentration injected into the cell. Chen-Guo hydrate model (Chen and Guo, 1998) was extended to calculate the pressure of methane hydrate formation in the presence of ammonia. It demonstrated that the model could be applied to these systems.

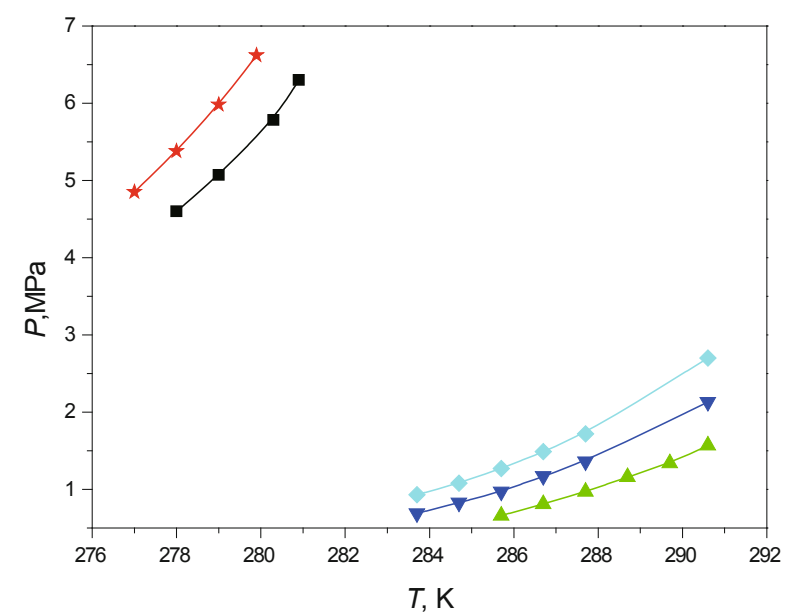

Fig. 3 Pressure-temperature phase equilibrium of methane hydrate formation in the presence of ammonia

$\star 3.17 \% \mathrm{NH}_{3}+\mathrm{H}_{2} \mathrm{O} ; 1.02 \% \mathrm{NH}_{3}+\mathrm{H}_{2} \mathrm{O} ; \quad 4.98 \% \mathrm{NH}_{3}+5.70 \% \mathrm{THF}+\mathrm{H}_{2} \mathrm{O}$; v2.99\% $\mathrm{NH}_{3}+5.82 \% \mathrm{THF}+\mathrm{H}_{2} \mathrm{O} ; \Delta \mathrm{THF}+\mathrm{H}_{2} \mathrm{O}$ 
Table 3 Methane hydrate formation pressures in the presence of ammonia

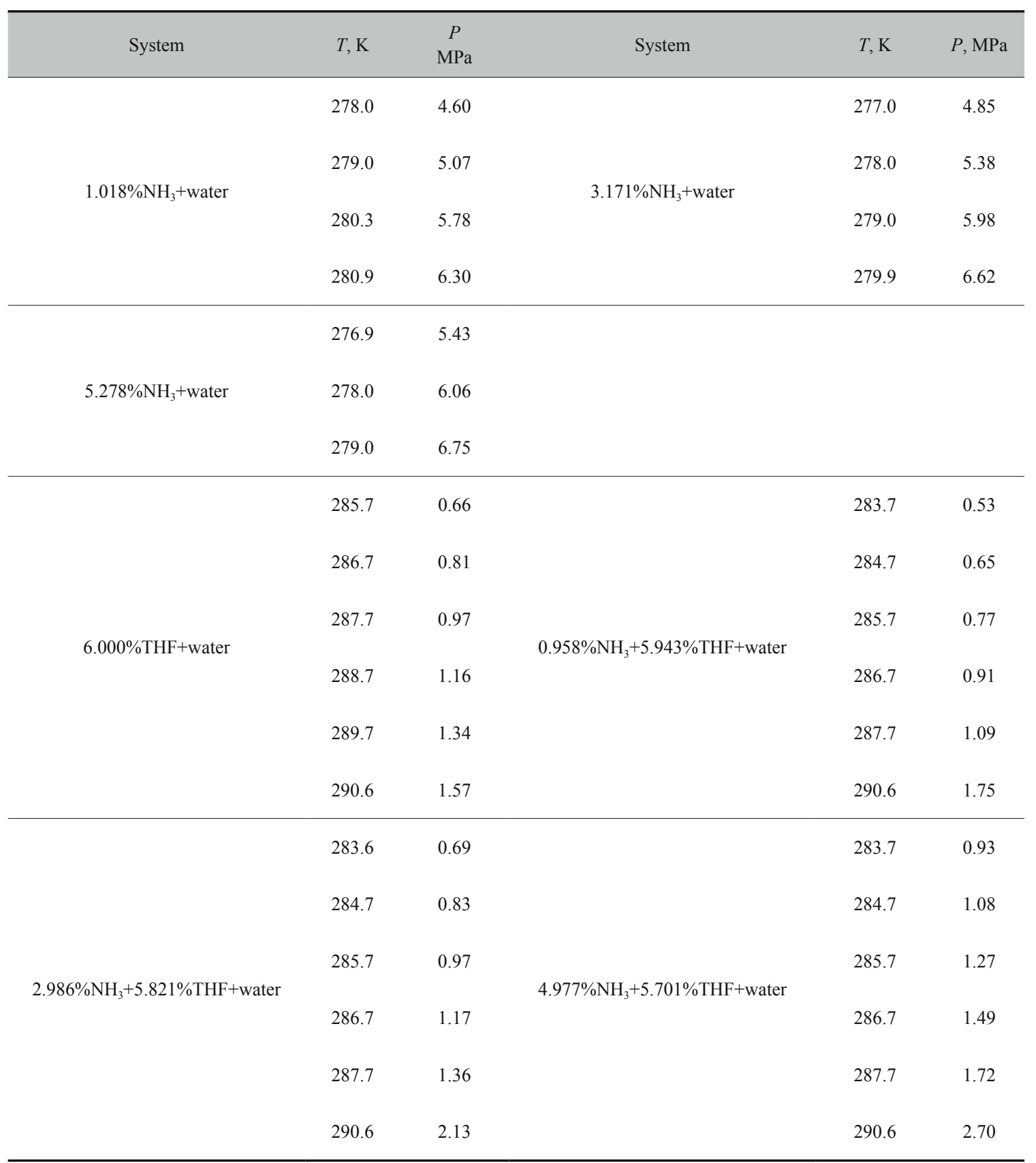

5.2 Primary experimental results of gas-liquid ratio and temperature on separation of ammonia synthesis vent gas by hydrate formation

The compositions of the gas mixture used in the experiment are listed in Table 4 . The separation reaction was carried out under a pressure of $8 \mathrm{MPa}$. The effects of gas-liquid ratio and temperature on the separation were investigated. The compositions of equilibrium vapor phase are listed in Table 5.

The results showed that the ammonia synthesis vent gas could be separated effectively by hydrate formation. The total mole fraction of $\left(\mathrm{H}_{2}+\mathrm{N}_{2}\right)$ in the equilibrium vapor was more than $92 \%$ and the fraction of $\mathrm{H}_{2}$ was up to or even more than
Table 4 Compositions of gas mixture in experiment

\begin{tabular}{ccccc}
\hline Gas & $\mathrm{H}_{2}$ & $\mathrm{~N}_{2}$ & $\mathrm{CH}_{4}$ & $\mathrm{Ar}$ \\
\hline Mole fraction, \% & 65.4 & 23.4 & 8.7 & 2.5 \\
\hline
\end{tabular}

$70 \%$. The temperature influenced the reaction greatly. The higher the temperature was, the greater the recovery percent of $\mathrm{H}_{2}$ would be. When the volume ratio of gas to liquid was $80: 1$ and the temperature was $283.15 \mathrm{~K}$, the total mole fraction of $\left(\mathrm{H}_{2}+\mathrm{N}_{2}\right)$ reached a maximum of $96.9 \%$. 
Table 5 Compositions of equilibrium vapor phase at $8 \mathrm{MPa}$

\begin{tabular}{|c|c|c|c|c|c|}
\hline Volume ratio of gas to liquid & $T, \mathrm{~K}$ & $\mathrm{H}_{2}, \%$ & $\mathrm{Ar}, \%$ & $\mathrm{~N}_{2}, \%$ & $\mathrm{CH}_{4}, \%$ \\
\hline \multirow{5}{*}{110} & 278.15 & 69.8 & 1.9 & 22.3 & 5.9 \\
\hline & 279.15 & 71.1 & 1.9 & 22.0 & 5.0 \\
\hline & 280.15 & 73.5 & 1.6 & 20.7 & 4.2 \\
\hline & 281.15 & 73.5 & 1.7 & 20.8 & 4.0 \\
\hline & 283.15 & 76.7 & 1.3 & 19.2 & 2.8 \\
\hline \multirow{5}{*}{100} & 278.15 & 71.4 & 1.9 & 20.9 & 5.8 \\
\hline & 279.15 & 71.8 & 1.8 & 21.5 & 4.9 \\
\hline & 280.15 & 73.6 & 1.7 & 20.6 & 4.1 \\
\hline & 281.15 & 75.2 & 1.7 & 20.1 & 3.1 \\
\hline & 283.15 & 77.3 & 1.3 & 18.8 & 2.6 \\
\hline \multirow{5}{*}{80} & 278.15 & 73.6 & 1.6 & 20.8 & 4.0 \\
\hline & 279.15 & 76.6 & 1.5 & 19.4 & 2.5 \\
\hline & 280.15 & 77.4 & 1.3 & 18.6 & 2.7 \\
\hline & 281.15 & 77.6 & 1.3 & 18.7 & 2.4 \\
\hline & 283.15 & 79.4 & 1.1 & 17.5 & 2.0 \\
\hline
\end{tabular}

\section{Conclusions}

Formation conditions for methane hydrate in the presence of ammonia and THF were investigated. The experimental results indicate that ammonia has an inhibitive effect on the hydrate formation. More ammonia in water would result in a higher pressure for methane to form hydrate. The calculated results showed that the Chen-Guo hydrate model fitted these systems well. The presence of THF could decrease the pressure of hydrate formation significantly, making hydrate available in industrial application of recycling the ammonia synthesis vent gas. The present work proved that this new method could be used to separate this gas mixture effectively, and the best operation conditions obtained for the simulated vent gas mixture was that volume ratio of gas to liquid 80:1 and temperature $283.15 \mathrm{~K}$, then the total mole fraction of $\left(\mathrm{H}_{2}+\mathrm{N}_{2}\right)$ in the gas phase could reach $96.9 \%$.

\section{Acknowledgement}

The financial support received from the National Natural Science Foundation of China $(20476058,20676146)$ and Ministry of Science and Technology of China (2006AA09A208, 2009CB219504) and Specialized Research Fund for the Doctoral Program of Higher Education (20070425001) are gratefully acknowledged.

\section{References}

Chatti I, Delahaye A and Fournaison L. Benefits and drawbacks of clathrate hydrates: A review of their areas of interest. Energy Conversion and Management. 2005. 46:1333-1343

Chen G J and Guo T M. A new approach to gas hydrate modeling. J. Chem. Eng. 1998. 71(8): 145-151

Clarke M A, Majumdar A and Bishnoi P R. Experimental investigation of carbon dioxide hydrate formation conditions in the presence of $\mathrm{KNO}_{3}, \mathrm{MgSO}_{4}$, and $\mathrm{CuSO}_{4}$. J. Chem. Eng. Data. 2004. 49: 14361439

Devarakonda S, Groysman A and Myerson A S. THF + water hydrate crystallization: An experimental investigation. J. Crystal Growth. 1999. 204: 525-538

Dholabhai P D and Bishnoi P R. Hydrate equilibrium conditions in aqueous electrolyte solutions: mixtures of methane and carbon dioxide. J. Chem. Eng. Data. 1994. 39: 191-194

Englezos P. Clathrate hydrates. Ind. Eng. Chem. Res. 1993. 32: 12511274

Florusse L J, Peters C J, Schoonman J, Hester K C, Koh C A, Dec S F, Marsh K N and Sloan E D. Stable low-pressure hydrogen clusters stored in a binary clathrate hydrate. Science. 2004. 306: 469-471

Hammerschmidt E G. Formation of gas hydrate in natural gas transmission lines. Ind. Eng. Chem. 1934. 8: 851-855

Hashimoto $\mathrm{S}$ and Murayama S. Thermodynamic and Raman 
spectroscopic studies on $\left(\mathrm{H}_{2}+\right.$ tetrahydrofuran + water $)$ and $\left(\mathrm{H}_{2}+\right.$ tetranbutyl ammonium bromide+water $)$ mixtures containing gas hydrates. Chem. Eng. Sci. 2006. 61: 7884-7888

Kim D Y, Park Y and Lee H. Tuning clathrate hydrates: Application to hydrogen storage. Catal. Today. 2007. 120: 257-261

Lee S, Liang L, Riestenberg D, West O R, Tsouris C and Adams E. $\mathrm{CO}_{2}$ hydrate composite for ocean carbon sequestration. Environ. Sci. Technol. 2003. 37: 3701-3708

Mahmoodaghdam E and Bishnoi P R. Equilibrium data for methane, ethane, and propane incipient hydrate formation in aqueous solutions of ethylene glycol and diethylene glycol. J. Chem. Eng. Data. 2002. 47: 278-281

Makogon Y F. Hydrate formation in the gas-bearing beds under permafrost conditions. Gazovaia Promyshlennost. 1965. 4:14-15

Makogon Y F. Hydrates of Natural Gas; Penn Well Books. Tulsa Oklahoma. 1981. 14-15

$\mathrm{Ng} \mathrm{H} \mathrm{J} \mathrm{and} \mathrm{Robinson} \mathrm{D} \mathrm{B.} \mathrm{Hydrate} \mathrm{formation} \mathrm{in} \mathrm{systems} \mathrm{containing}$ methane, ethane, propane, carbon dioxide or hydrogen sulfide in the presence of methanol. Fluid Phase Equilib. 1985. 21: 145-155

Rovetto L J, Strobel T A, Hester K C, Dec S F, Koh C A, Miller K T and Sloan E D. Molecular Hydrogen Storage in Novel Binary Clathrate
Hydrates at Near-Ambient Temperatures and Pressures. FY 2006 Annual Progress Report. DOE Hydrogen Program. 629-632

Sloan E D. Clathrate Hydrates of Natural Gas. Marcel Dekker: New York. 1990. 291-456

Song K Y and Kobayashi R. Final Hydrate Stability Conditions of a Methane and Propane Mixture in the Presence of Pure Water and Aqueous Solutions of Methanol and Ethylene Glycol. Fluid Phase Equilib. 1989. 47: 295-308

Strobel T A, Taylor C J, Hester K C, Dec S F, Koh C A, Miller K T and Sloan E D. Molecular hydrogen storage in binary $\mathrm{THF}_{-} \mathrm{H}_{2}$ clathrate hydrates. J. Phys. Chem. 2006. 110: 17121-17125

Sun C Y, Ma C F and Chen G J. Experimental and simulation of single equilibrium stage separation of (methane + hydrogen) mixtures via forming hydrate. Fluid Phase Equilib. 2007. 261: 85-91

Thakore J L and Holder G D. Solid-vapor azeotropes in hydrate-forming systems. Ind. Eng. Chem. Res. 1987. 26(3): 462-469

Zhang L W, Chen G J and Guo X Q. The partition coefficients of ethane between vapor and hydrate phase for (methane + ethane + water) and (methane + ethane + THF + water) systems. Fluid Phase Equilib. 2004. 225: 141-144

(Edited by Zhu Xiuqin) 